\title{
La importancia actual del artículo 822 del Código Civil español y su falta de reforma en el anteproyecto de ley por el que se reforma la legislación civil procesal en materia de discapacidad ${ }^{1}$
}

\author{
A importância atual do artigo 822 do Código Civil espanhol e sua falta de reforma \\ no anteprojeto de lei que reforma a legislação processual civil em matéria de \\ deficiência
}
The important spanish Civil Code article 822 and its lack of reform in the draft law reforming the civil procedural law in matters of disability

\section{Pedro Botello Hermosa*}

\section{Resumen}

\begin{abstract}
A través del presente artículo me cuestiono por qué el legislador actual no aprovechó el Anteproyecto de Ley por el que se reforma la legislación civil y procesal en materia de discapacidad que fue presentado ante el Consejo de Ministros en septiembre de 2018, para disipar las importantes incertidumbres jurídicas que la redacción actual del artículo 822 del Código civil plantea respecto a un derecho de enorme importancia para las personas con discapacidad, como es el derecho de habitación que, bien por voluntad del testador o bien por Ministerio de la ley, podrá establecerse a su favor sin que se compute en la legítima, siempre y cuando ostenten la condición de legitimario del causante.
\end{abstract}

Palabras claves: Derecho de habitación. Personas con Discapacidad. Anteproyecto de Ley por la que se reforma la legislación civil y procesal en materia de discapacidad. Oportunidad perdida.

\section{Resumo}

Neste artigo questiono por que o atual legislador não aproveitou o Projeto de Lei que reforma a legislação civil e processual em matéria de deficiência, que foi apresentado ao Conselho de Ministros em setembro de 2018, para dissipar as importantes incertezas jurídicas que a atual redação do artigo 822 do Código Civil levanta em relação a um direito de enorme importância para as pessoas com deficiência, como o é o direito de habitação, o qual, seja por vontade do testador, seja pelo Ministério da lei, poderá ser estabelecido a seu favor, sem ser computado no legítimo, desde que tenham o status de legitimar o falecido.

Palavras-chave: Direito de habitação. Pessoas com deficiência. Anteprojeto de lei para reforma da legislação civil e processual em matéria de deficiência. Oportunidade perdida.

\section{Abstract}

Through this article I question why the current legislator did not take advantage of the Draft Law reforming the civil and procedural legislation in matters of disability that was presented to the Council of Ministers in September 2018, to dissipate the important legal uncertainties that the current redaction of Civil Code Article 822 raises regarding a right of enormous importance for people with disabilities, such as the right of habitation that, without being computed in the legitimate, may be established in favor of the disabled legitimate either by the testator, or by the Ministry of Law.

Keywords: Right of habitation. People with disabilities. Draft Law reforming the Civil and Procedural Law in matters of disability. Lost opportunity.

El presente artículo se ha elaborado en el marco del Grupo de investigación SEJ617: Nuevas Dinámicas del Derecho Privado Español y Comparado. Doctor por la Universidad de Sevilla. Profesor del Centro San Isidoro, Adscrito a la Universidad Pablo de Olavide de Sevilla. Sevilla - Espanha. E-mail: pedrobh4@gmail.com. 


\section{Introducción}

La principal preocupación de los familiares de algunas personas con discapacidad, y de la inmensa mayoría de personas con su capacidad modificada judicialmente, ${ }^{2}$ es la de quién se ocupará de ellos una vez que su responsable fallezca.

Con la intención de solventar, al menos en parte, dicha preocupación, el legislador español aprobó hace ya más de 15 años la Ley $41 / 2003,{ }^{3}$ de 18 de noviembre, de Protección Patrimonial de las Personas con Discapacidad y de modificación del Código Civil, de la Ley de Enjuiciamiento Civil y de la Normativa Tributaria con esta finalidad (en adelante LPPD). A este respecto, expone Vivas Tesón $(2009$, p. 8) que

[...] dicha Ley permite prever y planificar el bienestar económico de las personas con discapacidad, adoptando soluciones de protección patrimonial que, en el futuro, puedan, eficazmente, complementar los ingresos económicos que ellas mismas obtengan por su trabajo o por pensiones públicas de diversa índole y, por consiguiente, permitirle vivir una mejor vida adulta. No es preciso esperar a formularse angustiosamente la pregunta: ¿Qué será de él/ella cuando no pueda hacerme cargo o me muera?, para iniciar la planificación económica de su etapa adulta, pues este proyecto de futuro puede comenzarse desde la niñez o adolescencia de la persona con discapacidad, contando, incluso, para ello, como tendremos ocasión de ver, con algunas ventajas fiscales.

\section{Mientras que González Porras (2005, p. 699-700) cuenta que}

[...] la reforma llevada a cabo por la Ley 41/2.003, de 18 de Noviembre, que lleva el título de Ley de Protección Patrimonial de las Personas con Discapacidad(...), es, a mi juicio, una de las más importantes, si no la de mayor calado entre las que han reformado el articulado de nuestro Código civil, y diré que pienso que es así porque afecta de manera directa a los tres pilares fundamentales del 'Sistema', que son 'la persona física' y además la persona física discapacitada, primer elemento sobre el que se apoya el Derecho civil (...), 'La familia' (...), y el 'patrimonio' como factor necesario para su desarrollo.

Pues bien, el presente trabajo tiene como objeto el estudio del contenido del actual artículo 822 del Código civil (en adelante C.c.), artículo que fue íntegramente introducido en nuestro C.c. a través de la LPPD, ${ }^{4}$ y la nueva redacción que para el mismo propone el Anteproyecto de Ley por la que se reforma la legislación civil y procesal en materia de discapacidad ${ }^{5}$ (en adelante APL), presentado ante el Consejo de Ministros en septiembre de 2018. Desde la promulgación de la LPPD, el artículo 822 del C.c. establece que:

La donación o legado de un derecho de habitación sobre la vivienda habitual que su titular haga a favor de un legitimario persona con discapacidad, no se computará para el cálculo de las legítimas si en el momento del fallecimiento ambos estuvieren conviviendo en ella.

Este derecho de habitación se atribuirá por ministerio de la ley en las mismas condiciones al legitimario discapacitado que lo necesite y que estuviera conviviendo con el fallecido, a menos que el testador hubiera dispuesto otra cosa o lo hubiera excluido expresamente, pero su titular no podrá impedir que continúen conviviendo los demás legitimarios mientras lo necesiten.

\footnotetext{
Aunque actualmente el C.c. en sus artículos dedicados a la materia sigue haciendo referencia al procedimiento de incapacitación y persona incapacitada, por mi parte a lo largo del presente artículo siempre usaré los términos de procedimiento de modificación de la capacidad y persona con capacidad modificada judicialmente, por ser éstos términos que también quedan comprendidos en nuestro Ordenamiento jurídico, concretamente en la Ley de Jurisdicción Voluntaria 15/2015.

Dicho esto entiendo oportuno resaltar que en el Anteproyecto de Ley por la que se reforma la legislación civil y procesal en materia de discapacidad va un paso más allá y apuesta por un nuevo término como es el de persona con discapacidad necesitada de apoyo, y todo ello, como no, para cumplir con el espíritu del artículo 12 de la Convención donde se apuesta por el apoyo y no por la limitación en la capacidad de las personas con discapacidad, pero dado que dicho Anteproyecto sigue siendo a día de hoy eso, un Anteproyecto de Ley, vuelvo a reiterar que la terminología más apropiada en nuestro actual Ordenamiento jurídico es la comprendida en la Ley 15/2015 de Jurisdicción Voluntaria.

Publicada en el B.O.E. núm. 277, de 19 noviembre de 2003.

El hasta entonces artículo 822 del C.c. pasó a convertirse en el párrafo tercero del artículo 821, y así sigue siendo en la actualidad.

Entre noviembre de 2015 y diciembre de 2017 la Sección Primera, de lo Civil, de la Comisión General de Codificación trabajó en la elaboración de un texto que finalmente fue presentado a la consideración del Ministro de Justicia el 20 de febrero de 2018 , no siendo hasta el 21 de septiembre de 2018 cuando el conocido como APL, fue presentado a la consideración del Consejo de Ministros, que lo informó en primera vuelta.
} 
El derecho a que se refieren los dos párrafos anteriores será intransmisible.

Lo dispuesto en los dos primeros párrafos no impedirá la atribución al cónyuge de los derechos regulados en los artículos 1406 y 1407 de este Código, que coexistirán con el de habitación.

De su contenido se desprende que el artículo 822 regula un derecho importantísimo ${ }^{6}$ que existe en nuestra sociedad a favor de las personas con discapacidad, como es el derecho de habitación sobre la vivienda habitual que los testadores españoles con legitimarios con discapacidad podrán establecer a favor de éstos, siempre y cuando ambos conviviesen en el inmueble al momento de la muerte del testador, y éste no se haya opuesto a ello, afectando por tanto tal medida introducida por la LPPD al régimen sucesorio español ${ }^{7}$ con la intención de proteger a las personas con discapacidad.

Como bien expone Donado Vara (2018, p. 1567), el derecho real limitado de habitación faculta al habitacionista - persona beneficiaria de este derecho - a ocupar en vivienda ajena las piezas necesarias para él y, en su caso, para su familia (cónyuge, pareja de hecho, cuidador...) de forma vitalicia, salvo que el título constitutivo disponga algo distinto.

Junto a este enorme importancia práctica se ha de destacar que el legitimario con discapacidad que se beneficie de este derecho seguirá teniendo la misma cuota de legítima que el resto de herederos ${ }^{8} \mathrm{o}$ lo que es lo mismo, que dicho derecho de habitación sirve para vulnerar el principio histórico sucesorio español de la intangibilidad de la legítima estricta, y todo ello en beneficio de las personas con discapacidad.

Así, Ragel Sánchez (2013, p. 6097) expone que

Al igual que sucede con el supuesto de constitución ex lege del derecho de habitación a favor del legitimario discapacitado regulado en el art. 822.II, cuando la legítima estricta de los legitimarios que no sean discapacitados se pague con la atribución de la propiedad de la vivienda que era habitual del causante, dicha propiedad resultará gravada con el derecho de habitación y, al tratarse en este caso de un gravamen que la ley permite realizar al donante o testador, no entrará en juego el artículo 813.II CC que prohíbe gravar la legítima. Resulta entonces que las excepciones a la intangibilidad cualitativa de la legítima estricta aparecen claramente como una confirmación de la libertad de testar del causante, puesto que la Ley permite que el testador pueda imponer gravámenes sobre dicha legítima.

Por otra parte, desde un punto de vista práctico destaca el hecho de que en aquellos casos en los que el testador no se haya opuesto expresamente al derecho de habitación, éste se otorgará por ministerio de ley a favor de aquel legitimario con discapacidad que lo necesite, lo cual implica que en España, cualquier persona con discapacidad que lo necesite y que ostente la condición de legitimario respecto a un testador, tendrá por ley derecho a habitación en el inmueble que conviviese con el testador, siempre que éste no se hubiese opuesto expresamente.

En este sentido me permito traer a colación el contenido de la sentencia ${ }^{9}$ de la Audiencia Provincial de Vizcaya de 15 de noviembre, cuando expone que:

El art. 822 del Código civil fue reformado por Ley 41/2003, de 18 de noviembre, vigente al momento del fallecimiento de la madre del discapacitado; el precepto dispone en su párrafo 2, refiriéndose al derecho de habitación a favor del discapacitado que estuviera conviviendo con el causante en el domicilio familiar, que "este derecho de habitación se atribuirá por ministerio de la Ley en las mismas condiciones al legitimario discapacitado que lo necesite y que estuviera conviviendo con el fallecido, a menos que el testador hubiera dispuesto otras cosa o lo hubiera excluido expresamente; pero su

\footnotetext{
Y por desgracia no todo lo conocido que debiera por el colectivo de personas con discapacidad.

También se incluyen como medidas introducidas por la LPPD que afectan al régimen sucesorio español las facultades concedidas por el testador a favor del cónyuge supérstite para mejorar y distribuir la herencia del premuerto entre los hijos o descendientes comunes; o, una nueva causa de indignidad sucesoria por no prestar los alimentos legales al pariente con discapacidad; o, la exención de traer a colación los gastos realizados por los padres y ascendientes para cubrir las necesidades especiales de sus hijos o descendientes con discapacidad; así como, la sustitución fideicomisaria especial que puede establecerse a favor de los descendientes incapacitados judicialmente sobre todo el tercio de legítima estricta. Porque el derecho de habitación expuesto no se computará para el cálculo de las legítimas.

JUR\2012\171718.
} 
titular no podrá impedir que continúen conviviendo los demás legitimarios mientras lo necesiten.

Esta Ley se dictó para protección de las personas discapacitadas estableciendo la posibilidad de que sus progenitores otorgaran disposiciones testamentarias que los protegieran cuando falten o disponiendo, como es el caso, un haz de derechos imperativos ( por ministerio de la Ley ) que asisten al discapacitado y que prevalecen frente a los intereses de los restantes coherederos, a menos que el causante haya dispuesto otra cosa o lo hubiera excluido expresamente.

El causante no ha dispuesto otra cosa ni lo ha excluido expresamente; de la literalidad del precepto debemos concluir que fuera de los casos en que se excluya o de aquellos otros en que el testador disponga a favor del discapacitado de otra manera, entra en aplicación la Ley y le asiste el derecho de habitación del domicilio del causante, derecho que se extinguirá por muerte del usuario. [...]

Por tanto nos encontramos con una persona que entra dentro del ámbito de la mencionada Ley y que necesita de la vivienda familiar al no disponer de otra, siendo una carga de la herencia la atribución del domicilio familiar en los términos señalados por la Ley y sin que concurra ninguna de las circunstancias que la excluya.

En tal sentido y habida cuenta que el interés del discapacitado representado por el Instituto Tutelar de Bizkaia debe prevalecer sobre el de los restantes coherederos, entrañando el derecho de habitación una carga que por ministerio de la Ley reciben al heredar, los argumentos de la sentencia recurrida no pueden ser compartidos por esta Sala y debe ser revocada, estimado el recurso y reconocido el derecho de Don Fernando al uso de la vivienda familiar.

Existen normas tanto en la Ley de Arrendamientos Urbanos como en la Ley de Propiedad Horizontal, encaminadas a atender las necesidades de las personas con algún tipo de discapacidad en cuanto a la adecuación de su vivienda, entiéndase, por ejemplo, su accesibilidad. Sin embargo, lo que se consiguió tras la promulgación de la LPPD fue la protección de las personas con discapacidad mediante la adjudicación del uso de una vivienda sin que nadie pueda arrebatárselo bajo ningún concepto, ya sea por voluntad del testado o bien por ministerio de la ley.

Por todo ello, entiendo oportuno que el presente artículo se centre en el estudio de un derecho tan importante como el que ofrece nuestro actual artículo 822 a las personas con discapacidad, así como en la nueva redacción que del mismo propone el APL, si bien el grueso del articulado ${ }^{10}$ de la reforma del Código civil propuesto en el mencionado Anteproyecto de Ley tiene como finalidad la eficaz implementación en nuestro Ordenamiento jurídico del artículo 12 de la Convención de Naciones Unidas sobre los Derechos de las Personas con Discapacidad en relación con las medidas de apoyo que éstas puedan necesitar para el ejercicio de su capacidad jurídica ${ }^{11}$ en plenitud de igualdad con los demás.

10 De hecho comienza el APL en su Exposición de Motivos afirmando que "La presente reforma del Código Civil, de la Ley de Enjuiciamiento Civil, la Ley Hipotecaria y la Ley del Registro Civil pretende dar un paso decisivo en la adecuación de nuestro ordenamiento jurídico a la Convención internacional sobre los derechos de las personas con discapacidad, hecha en Nueva York el 13 de diciembre de 2006 , tratado internacional que en su artículo 12 proclama que las personas con discapacidad tienen capacidad jurídica en igualdad de condiciones con las demás en todos los aspectos de la vida, y obliga a los Estados Parte a adoptar las medidas pertinentes para proporcionar acceso a las personas con discapacidad al apoyo que puedan necesitar en el ejercicio de su capacidad jurídica".

11 La cual a día de hoy, y tras la Convención, engloba tanto la capacidad jurídica (entendida como aptitud estática del sujeto, a quien, por el mero hecho de ser persona y por su dignidad como tal, el Ordenamiento jurídico le atribuye derechos y obligaciones, tanto en la esfera personal como en la patrimonial) como la capacidad de obrar (entendida como aptitud de poner en movimiento por sí mismo los poderes y facultades que surgen de sus propios derechos, y en general, para desenvolverse con autonomía en la vida jurídica). 


\section{2 Única diferencia entre al actual artículo 822 y el propuesto en el anteproyecto}

Basta con leer el título de este segundo apartado para intuir que, en mi opinión, la nueva redacción propuesta por el APL para el derecho de habitación de las personas con discapacidad es insuficiente.

Y es que, al comparar la redacción actual del artículo $822^{12}$ del C.c. con la que propone el APL en el apartado $38^{13}$ de su artículo primero (modificando solo los párrafos primero y segundo del artículo 822 ), llego a la conclusión de que lo único que diferencia a ambas redacciones es el nuevo titular del derecho de habitación, el cual en el C.c. actual es una persona con discapacidad, mientras que para el APL será aquella persona que se encuentre en una situación física o psíquica que le impida desenvolverse de forma autónoma.

Pero, ¿quiénes son las personas que se encuentran en una situación física o psíquica que les impide desenvolverse de forma autónoma? ¿Dónde aparece su regulación legal?

Como en el Código civil, ni tampoco en el APL, no se define quiénes son esas personas que no pueden desenvolverse de forma autónoma por su situación física o psíquica, entiendo que hay que acudir a la 39/2006, de 14 de diciembre, de Promoción de la Autonomía Personal y Atención a las personas en situación de dependencia, en cuyo artículo 2 dedicado a las definiciones se recoge lo siguiente:

1.- Autonomía: la capacidad de controlar, afrontar y tomar, por propia iniciativa, decisiones personales acerca de cómo vivir de acuerdo con las normas y preferencias propias así como de desarrollar las actividades básicas de la vida diaria.

4. Necesidades de apoyo para la autonomía personal: las que requieren las personas que tienen discapacidad intelectual o mental para hacer efectivo un grado satisfactorio de autonomía personal en el seno de la comunidad.

Llegados a este punto se me ocurren varias cuestiones al respecto: ¿ha de fijar concretamente la resolución administrativa que fija la discapacidad de una persona si ésta puede o no puede desenvolverse de forma autónoma? La persona con discapacidad que sí pueda hacerlo, y que hasta ahora es beneficiaria del derecho de habitación que estudiamos por ser una persona con discapacidad, ¿dejará de ostentar tal condición de beneficiario?

\section{Interrogantes que existen con la redacción actual del artículo 822 y que no se disipan con la redacción propuesta en el anteproyecto}

Como ya sabemos, el actual artículo 822 del C.c. fue introducido por la LPPD, y las dos notas características que, de forma unánime, nuestros autores otorgan a dicha norma a la hora de definirla son dos: gran importancia dentro de nuestro Ordenamiento jurídico y deficiente redacción técnico-jurídica dada por el legislador.

Es Leña Fernández (2005, p. 183) quien mejor refleja la opinión generalizada de nuestra doctrina sobre la LPPD cuando expone que

12 Párrafos primero y segundo del artículo 822:

La donación o legado de un derecho de habitación sobre la vivienda habitual que su titular haga a favor de un legitimario persona con discapacidad, no se computará para el cálculo de las legítimas si en el momento del fallecimiento ambos estuvieren conviviendo en ella.

Este derecho de habitación se atribuirá por ministerio de la ley en las mismas condiciones al legitimario discapacitado que lo necesite y que estuviera conviviendo con el fallecido, a menos que el testador hubiera dispuesto otra cosa o lo hubiera excluido expresamente, pero su titular no podrá impedir que continúen conviviendo los demás legitimarios mientras lo necesiten.

13 Apartado treinta y ocho, artículo primero:

Se da nueva redacción a los párrafos primero y segundo del artículo 822, con el siguiente texto:

"La donación o legado de un derecho de habitación sobre la vivienda habitual que su titular haga a favor de un legitimario que se encuentre en una situación física o psíquica que le impida desenvolverse de forma autónoma, no se computará para el cálculo de las legítimas si en el momento del fallecimiento ambos estuvieren conviviendo en ella.

Este derecho de habitación se atribuirá por ministerio de la ley en las mismas condiciones al legitimario que se halle en la situación prevista en el párrafo anterior, que lo necesite y que estuviere conviviendo con el fallecido, a menos que el testador hubiera dispuesto otra cosa o lo hubiera excluido expresamente, pero su titular no podrá impedir que continúen conviviendo los demás legitimarios mientras lo necesiten." 
[...] desde el punto de vista técnico-jurídico, la Ley es muy imperfecta, con demasiadas imprecisiones, lagunas clamorosas y una evidente cortedad de alcance en las soluciones planteadas, lo que ha llevado a SEDA HERMOSÍN a calificarla, como un verdadero parto de los montes. No era así en su primer anteproyecto, pero, sin duda, las sucesivas y numerosas manos (y mentes) puestas sobre ella han conseguido realizar este verdadero estropicio.

Bien, pues, a pesar de todo eso, o mejor, por encima de todo eso, creo que hay que saludarla como un avance importante en lo que hace referencia al entorno jurídico del discapacitado, y ello, porque abre espacios de libertad en ese entorno, unos espacios de libertad que permiten una mayor igualación, sobre todo en el ámbito patrimonial, con los plenamente capaces y que llevamos reclamando, desde hace ya bastantes años, algunos de los que nos venimos ocupando de estas materias. [...] Por eso mi posición, respecto a ella y por encima de sus muchas imperfecciones e insuficiencias formales y materiales, es sumamente favorable: aprecio en ella su apertura a espacios de libertad.

En este sentido, la redacción dada al artículo 822 por la LPPD es un claro ejemplo de la deficiente redacción técnica de la norma, ya que desde entonces a la hora de hablar del derecho de habitación a favor de las personas con discapacidad que recoge nuestro C.c. se plantean una serie de dudas respecto a su alcance, dudas que no han sido resueltas con la nueva redacción que de dicho artículo propone el APL.

\subsection{Legitimario con discapacidad como posible beneficiario}

Expone el artículo 822 que "la donación o legado de un derecho de habitación sobre la vivienda habitual que su titular haga a favor de un legitimario persona con discapacidad, no se computará para el cálculo de las legítimas si en el momento del fallecimiento ambos estuvieren conviviendo en ella."

Por tanto, a diferencia de lo que ocurre con la sustitución fideicomisaria especial introducida por la LPPD, de la cual únicamente podrán disfrutar como beneficiarios los hijos o descendientes judicialmente incapacitados del testador, en el derecho de habitación a favor de las personas con discapacidad regulado en el artículo 822 el beneficiario podrá ser cualquier legitimario con discapacidad del causante, es decir, serán posibles beneficiarios de esta medida de protección (siempre que tengan la consideración de persona con discapacidad) no sólo sus hijos o descendientes, sino también sus padres o ascendientes, o incluso su cónyuge viudo, ya que todos ellos pueden llegar a tener la condición de legitimarios.

Sin embargo, llegados a este punto hemos de aclarar que, tal y como expone el artículo 807 del C.c., son legitimarios (o herederos forzosos):

$1 .^{\circ}$ Los hijos y descendientes respecto de sus padres y ascendientes.

2. A falta de los anteriores, los padres y ascendientes respecto de sus hijos y descendientes.

3. ${ }^{\circ}$ El viudo o viuda en la forma y medida que establece este Código.

Dicho de otra forma, sólo y exclusivamente cuando no haya hijos o descendientes del causante serán legitimarios sus padres o ascendientes, lo cual implica que una persona con hijos no puede establecer el derecho de habitación del 822 a favor de su padre con discapacidad, ${ }^{14}$ ya que en este caso los legitimarios del causante son sólo y exclusivamente sus hijos. En tal sentido, Díaz Alabart (2006, p. 25) considera que

\footnotetext{
Aunque en la mayor parte de los casos los legitimarios discapacitados que se beneficien de la excepción del art. 822 serán los hijos o descendientes, también podrían hacerlo el cónyuge viudo, y - si faltaran los hijos o descendientes -, los padres o ascendientes. Con toda razón se ha señalado que, pese a la afirmación de la Exposición de Motivos de la Ley 41/2003 de querer proteger a las personas de edad, al exigir la condición de legitimario al discapacitado habitacionista, lo cierto es que los ascendientes, sólo podrán gozar del derecho del art. 822 CC, en el supuesto de que no existan descendientes. Dándose la paradoja de que la Ley $41 / 2003$, cuando protege a los ascendientes discapacitados, es en la situación en que más protegidos estaban ya; cuando tienen la condición de legitimarios.
}

14 No sería legitimario del causante, ya que éste tiene hijos. 
Pero más llamativa resulta incluso la exclusión de los nietos con discapacidad como beneficiario del derecho de habitación que venimos estudiando en aquellos casos en los que sus padres vivan.

Y es que, establecen los artículos 932 y 933 del C.c., que los hijos del difunto le heredarán siempre por su derecho propio, mientras que los nietos y demás descendientes heredarán por derecho de representación; o dicho de otra forma, los nietos sólo se considerarán legitimarios cuando su padre (hijo del causante) le premuera.

Es decir, que con la redacción actual del artículo 822 del C.c., aunque un testador quisiera beneficiar con el derecho que venimos estudiando a su nieto con discapacidad no podría si el padre ${ }^{15}$ de éste también viviese. En la misma línea expone Serrano García (2008, p. 491-492) que "El donatario o legatario tiene que ser un discapacitado con derecho a legítima (descendiente, ascendiente o cónyuge); no cabe por vía de este legado el derecho de habitación sobre la vivienda habitual al nieto, viviendo el hijo (el padre es el legitimario, y no el nieto)."

Llegados a este punto considero que el APL era la ocasión perfecta para otorgar una nueva redacción al artículo 822 con la intención de conseguir que no sólo puedan beneficiarse de un derecho tan importante los ascendientes y descendientes legitimarios con discapacidad, sino que pudiesen hacerlo también aquellos ascendientes y descendientes con discapacidad que no fueran legitimarios.

En dicha situación se encuentran en la actualidad los cónyuges supérstites con discapacidad del causante, los cuales, son siempre considerados legitimarios, independientemente de que concurran con ascendientes o con descendientes del causante, ya que mientras que el artículo 834 del C.c. expone que "El cónyuge que al morir su consorte no se hallase separado de éste legalmente o de hecho, si concurre a la herencia con hijos o descendientes, tendrá derecho al usufructo del tercio destinado a mejora", el 837, por su parte, expone que "No existiendo descendientes, pero sí ascendientes, el cónyuge sobreviviente tendrá derecho al usufructo de la mitad de la herencia".

Llegados a este punto me gustaría resaltar que tal vez el APL era la ocasión perfecta para equiparar a cualquier ascendiente o descendiente con discapacidad del causante con el cónyuge supérstite, lo cual equivaldría a no exigirle a aquéllos la condición de legitimarios para poder beneficiarse de este derecho de habitación, sino que el único requisito fuese el de ostentar la condición de persona con discapacidad.

\subsection{La vivienda habitual como objeto del derecho de habitación legado o donado}

También exige el primer párrafo del artículo 822 del C.c. en su primer párrafo que el derecho de habitación donado o legado tenga por objeto la vivienda habitual, y de ahí que dicho derecho no surtirá efecto cuando la donación o el legado del derecho de habitación a persona legitimaria con discapacidad se produzca sobre otra vivienda del causante que no sea la habitual. Pero en este sentido lo primero qué podemos cuestionarnos es: ¿qué se entiende por "vivienda habitual" para este tipo de supuestos? Si un causante vive con su legitimario con discapacidad seis meses en un domicilio, y seis meses en otro, ¿cuál de ellos será considerada vivienda habitual a los efectos del 822 del C.c.?

Lo primero que debemos aclarar es que, aunque la redacción del 822 pueda hacer pensar que el derecho de habitación recaerá sobre toda la vivienda habitual, lo cierto es que el referido derecho real únicamente puede alcanzar a alguna habitación de la misma. En tal sentido narra García Herrera (2018, p. 128) que

el hecho de legar un derecho de habitación sobre una vivienda no implica, sin más, que dicho derecho real deba extenderse a la totalidad de su supericie. Si en el título constitutivo del derecho no se indica o especifica el alcance y extensión en que deba ejercitarse, habrá que acudir a la disposición contenida en el artículo 524 del Código civil, de acuerdo con el cual "La habitación da a quien tienen

15 Hijo del testador, por tanto su legitimario. 
este derecho la facultad de ocupar en una casa ajena las piezas necesarias para sí y para las personas de su familia", debiendo entenderse que el término "familia" no sólo abarca a la familia en sentido estricto y reducido, constituida por el cónyuge e hijos no emancipados, sino que se extiende a las demás personas que normalmente viven o deben vivir con el habitacionista; no engloba, por lo tanto, a todos los familiares y mucho menos a las amistades de éstos.

O en la misma línea Rodríguez de Almeida (2017, p. 2652) define el derecho de habitación como

\begin{abstract}
ese derecho real personalísimo que faculta a su titular a ocupar con finalidad de alojamiento una pieza o piezas de casa ajena. Como hemos dicho es un verdadero derecho real que limita las facultades de uso del propietario del inmueble, y que tiene oponibilidad erga omnes, por ejemplo frente a los sucesivos adquirentes del inmueble gravado, por lo que debe, y puede, inscribirse en el Registro de la Propiedad.
\end{abstract}

Por otro parte, en mi opinión, el legislador del 2003 no estuvo muy acertado al restringir exclusivamente la donación o legado de habitación sobre la vivienda habitual, ya que, con ello, puede llegar a perjudicar sin ninguna necesidad tanto a la propia persona con discapacidad, como al resto de colegitimarios.

Imaginemos, por ejemplo, el caso en el que el causante vive los últimos años de su vida con su legitimario con discapacidad en una casa muy grande en la playa, pero al mismo tiempo tiene un piso pequeño en la ciudad perfectamente habilitado para dicho legitimario.

En tal supuesto, aunque el causante quisiera, no puede concederle el derecho de habitación sobre el piso de la ciudad al legitimario con discapacidad ya que la vivienda habitual sería la casa de la playa, por tanto sólo sobre dicho inmueble podría establecer tal derecho, lo cual perjudicaría al resto de colegitimarios (la casa de la playa puede tener más valor económico y facilidad a la hora de enajenarse, pero si tiene un derecho de habitación gravándola su enajenación será más complicada), lo cual podría incluso suponer que el causante finalmente apueste por no establecer el derecho de habitación sobre la casa de la playa a favor del legitimario con discapacidad para no acabar perjudicando al resto de legitimarios.

¿Por qué no se aprovechó el APL para otorgar un nuevo alcance al derecho de habitación recogido en el artículo 822, con la finalidad de superar su actual limitación sobre la vivienda habitual?

\title{
3.3 La convivencia exigida entre causante y beneficiario
}

Igualmente se exige en el texto del C.c. que para que un legitimario con discapacidad pueda beneficiarse del artículo 822 debe convivir con el causante en el momento del fallecimiento de éste, tal y como recoge dicho artículo en su primer párrafo cuando expone que la donación o legado de un derecho de habitación sobre la vivienda habitual que su titular haga a favor de un legitimario persona con discapacidad, no se computará para el cálculo de las legítimas si en el momento del fallecimiento ambos estuvieren conviviendo en ella.

En mi opinión, con tal exigencia restringe mucho las posibilidades de los familiares con discapacidad del testador de verse beneficiados por el derecho de habitación especial, ya que, por ejemplo, si no convivían al momento de su fallecimiento, un abuelo no podrá beneficiar a un nieto legitimario con discapacidad con el derecho de habitación correspondiente.

A parte, y coincidiendo con Vivas Tesón (2009, p. 175), considero que con la exigencia legal de convivencia de la persona con discapacidad con el causante al fin y al cabo se actúa en contra de una de las finalidades de la Convención de Naciones Unidas de 13 de Diciembre de 2006 sobre los derechos de las personas con discapacidad, como es, precisamente, que todas las personas con discapacidad puedan vivir de forma autónoma e independiente.

Imaginemos el caso de personas con una discapacidad auditiva o visual del 65 por ciento, ${ }^{16}$ que ostentan la condición de legitimarios del causante, pero que han decidido independizarse y vivir su vida de

16 Lo cual la convierte en una persona con discapacidad beneficiaria de las medidas de protección patrimonial introducidas por la LPPD. 
forma autónoma. ¿Por qué no podrán beneficiarse en el futuro de un derecho de habitación en el domicilio del testador si fuese precisamente esta su voluntad, si cumple los requisitos de ser legitimario del causante y tener una discapacidad?

Esta situación, en mi opinión, podría fomentar que los padres no quisieran fomentar la autonomía e independencia de sus hijos con discapacidad, sino que justo al contrario luchasen porque éstos siempre viviesen con ellos, precisamente para que en un futuro sí puedan beneficiarse del derecho que centra el estudio del presente artículo.

Tal vez la intención del legislador de 2003 era que de esta medida de protección sólo y exclusivamente pudiesen beneficiarse aquellas personas que sufren una discapacidad tan severa que les impida desarrollar una vida autónoma e independiente, situación ésta que parece que sí va a quedar resuelta con el nuevo contenido del 822 propuesto en el APL, ya que en el Anteproyecto se fija como posible beneficiario del derecho de habitación a aquella persona que se encuentre en una situación física o psíquica que le impida desenvolverse de forma autónoma, definición más cercana al tipo de persona que seguramente quería proteger el legislador de 2003 con este derecho, aunque se limitó a definirla como persona con discapacidad.

\subsection{Su condición de legado legal o por ministerio de la ley}

Esta puede ser, en mi opinión, la característica más importante que ofrece el derecho de habitación que contempla desde 2003 nuestro C.c. en su artículo 822, ya que expone en su segundo párrafo que:

\footnotetext{
Este derecho de habitación se atribuirá por ministerio de la ley en las mismas condiciones al legitimario discapacitado que lo necesite y que estuviera conviviendo con el fallecido, a menos que el testador hubiera dispuesto otra cosa o lo hubiera excluido expresamente, pero su titular no podrá impedir que continúen conviviendo los demás legitimarios mientras lo necesiten.
}

Es decir, que siempre que la persona con discapacidad lo necesite es el C.c. el que le atribuye tal derecho de habitación con el mismo alcance que si lo hubiese establecido a su favor el testador, por lo que este derecho de habitación por ministerio de la ley tampoco se computará a la hora de calcular la legítima de los herederos forzosos del causante.

Por tanto podemos llegar a la conclusión de que, cualquier legitimario con discapacidad que conviva con el causante en su vivienda habitual, se beneficiará del derecho de habitación del artículo 822 sin necesidad de que así lo haya establecido el testador, siempre y cuando se cumpla una triple condición, condiciones que no se exigen para el derecho de habitación a favor del legitimario con discapacidad que el testador haya establecido como donación o legado, y que son:

$1^{\text {a }}$.- Que el legitimario con discapacidad necesite este derecho de habitación.

Pero, ¿cuándo sabemos si la persona en cuestión necesita o no la vivienda?

Particularmente entiendo que con ello se refiere el legislador a que no disponga de otro alojamiento, ni de recursos económicos que le permitan acceder a ello (ya sea mediante arrendamiento o adquiriéndola).

Es decir, que la persona con discapacidad que tenga concedida una pensión por tal motivo, y que pueda pagarse al menos una habitación en un piso compartido, no será entonces beneficiaria, ¿no?

O la persona con discapacidad que en base a dicha herencia se calcule que puede adjudicarse en la misma $30.000 €$, por ejemplo, tampoco podrá adjudicársele tal derecho por ministerio de ley porque podrá hacer frente con dicha cantidad de dinero a, al menos, una habitación en un piso compartido durante varios años, ¿no?

Todo este tipo de interrogantes considero que podían haber sido resueltos mediante una nueva redacción más completa del artículo 822 a través del APL.

$2^{\mathrm{a}}$.- Que el testador no haya excluido expresamente el legado legal al que nos referimos, o haya dispuesto otra cosa. 
Por tanto, podemos pensar que en realidad, la voluntad del testador no estará tan ausente ya que podía haberse opuesto mediante una manifestación o disposición en el testamento para prohibir la posibilidad del legado legal, aunque parece que la pregunta correcta es: ¿realmente es conocedora la sociedad española de que aquéllos que convivan con algún legitimario con discapacidad que necesite una habitación y no hagan testamento, o no se opongan expresamente a ello, acabarán otorgándole el tan mencionado derecho de habitación por ley sobre la vivienda en la que ambos convivían?

$3^{a}$ El legitimario con discapacidad titular del derecho de habitación no podrá impedir que continúen conviviendo con él en el inmueble los demás legitimarios mientras lo necesiten.

Con este último límite el legislador intenta salvaguardar un poco más la figura del co-legitimario no beneficiado, o mejor dicho, gravado, con el derecho de habitación por ministerio de la ley, el cual ya experimenta un perjuicio como consecuencia de no poder computar el legado del derecho de habitación para el cálculo de las legítimas del beneficiado, como para que, además, se le pueda obligar a abandonar inmediatamente la que también viene siendo su vivienda habitual.

Eso sí, queda claro que la persona con discapacidad que disfruta del derecho de habitación por ministerio de la ley ${ }^{17}$ no puede impedir que continúen conviviendo con ella en la vivienda los demás colegitimarios "mientras" lo necesiten.

¿Qué debe entenderse por necesidad del resto de colegitimarios en tal sentido? ¿Podrán incluirse aquéllos que estén en paro? ¿O aquellos cuyos ingresos no sean lo suficientemente altos como para afrontar el pago del alquiler de un piso, pero en cambio si pudiese afrontar el alquiler de una habitación en otra vivienda que no sea la del causante? ¿Y la familia del colegitimario que necesite una habitación en el domicilio del causante, podrá instalarse también en dicha habitación?

Dudas, dudas y más dudas que, por desgracia, seguirán planteándose con la nueva redacción del artículo 822 del C.c. propuesta en el APL.

\section{Conclusiones}

La enorme importancia del derecho de habitación a favor de las personas con discapacidad que desde 2003 existe en nuestro Ordenamiento jurídico dada a la nueva redacción que la LPPD otorgó al artículo 822 del C.c. (el hasta entonces artículo 822 pasó a formar parte del actual 821) destaca en un doble sentido:

$1^{\circ}$.- La donación o legado de dicho derecho no se computará para el cálculo de las legítimas si en el momento del fallecimiento el testador y la persona con discapacidad conviviesen en la vivienda, lo cual atenta contra el principio histórico del Derecho sucesorio español de la intangibilidad de la legítima.

$2^{\circ}$.- Dicho derecho de habitación se establece por ministerio de la ley siempre y cuando el legitimario con discapacidad lo necesite y estuviese conviviese en el inmueble con el causante cuando este fallezca, a menos que el testador hubiera dispuesto otra cosa o lo hubiera excluido expresamente.

Pero si es destacable la enorme importancia de tal derecho, también lo es la deficiente redacción que al mismo le otorgó el legislador del 2003 en el referido artículo, el cual, desde su inclusión en el C.c. viene despertando una serie de interrogantes de gran calado jurídico que, en mi opinión, podrían haberse solucionado, o al menos haberse intentado, con el APL, el cual tiene precisamente como finalidad la reforma de la legislación civil en materia de discapacidad, y sin embargo, en dicho Anteproyecto la única modificación que se hace respecto a la redacción actual del artículo 822 es la sustitución del término personas con discapacidad por el de persona que se encuentre en una situación física o psíquica que le impida desenvolverse de forma autónoma como posibles beneficiarios del derecho que regula.

¿Por qué no se aprovechó la ocasión para otorgar a través del APL una nueva redacción más amplia y concisa al actual artículo 822 que disipase las dudas existentes respecto a un derecho tan importante como el que tratamos en el presente artículo?

17 Que es un derecho vitalicio, mientras que el otorgado por el causante puede ser temporal, dependiendo de la voluntad de éste. 


\section{Bibiliografía}

DÍAZ ALABART, S. El discapacitado y la tangibilidad de la legítima: fideicomiso, exención de colación y derecho de habitación (Ley 41/2.003, de 18 de Noviembre, de protección patrimonial de personas con discapacidad). In: VARGAS MUÑOZ, J. P. de (coord.). Protección jurídica patrimonial de las personas con discapacidad. [S.I]: Wolters Kluwer, 2006. p. 53-112.

DONADO VARA, Araceli. El legado o donación de derecho de habitación en el caso de un descendiente mayor de edad con discapacidad: controversias ante la aplicabilidad de una novedad legislativa sucesoria y contractual. Revista Crítica de Derecho Inmobiliario, Madrid, año 94, n.767, p. 1557-1582, mayo 2018.

GARCÍA HERRERA, Vanessa. EI legado de habitación a favor del legitimario discapacitado. Madrid: Editorial Dykinson, 2018.

GONZÁLEZ PORRAS, José Manuel. Algunas cuestiones sobresalientes en la reforma del Código Civil sobre la protección de las personas discapacitadas o incapacitadas. In: CASADO RAIGÓN, Rafael; GALLEGO DOMÍNGUEZ, Ignácio (coord.). Personalidad y capacidad jurídicas: 74 contribuciones con motivo del XXV aniversario de la Facultad de Derecho de Córdoba. Córdoba: Universidad de Córdoba, 2005. v. 2. p. 697-710.

RODRÍGUEZ DE ALMEIDA, Maria Goñi. Determinación del derecho de habitación. Revista Crítica de Derecho Inmobiliario, Madrid, año 87, n. 727, p. 2844-2857, sept. 2017.

LEÑA FERNÁNDEZ, R. Posibilidades testamentarias y otras disposiciones en materia de sucesiones que ofrece la Ley 41/2003. Cuadernos de Derecho Judicial, Madrid, n. 20, p. 179-272, 2005.

RAGEL SÁNCHEZ, Luis Felipe. Comentario al artículo 822. In: RODRíGUEZ-CANO, Rodrigo Bercovitz (dir.). Comentarios al Código Civil. Valência: Editorial Trant Lo Blanch, 2013. t. V.

SERRANO GARCÍA, I. Protección Patrimonial de las personas con discapacidad: tratamiento sistemático de la Ley 41/2.003. Madrid: Iustel, 2008.

VIVAS TESÓN, I. La protección económica de la discapacidad. Barcelona: Bosch, 2009.

Recebido em: 02/08/2019

Aprovado em: 08/09/2019 